\title{
THE RELATIONSHIP BETWEEN CULTIVATED LAND CHANGE AND ECONOMIC DEVELOPMENT BASED ON GIS IN HENAN PROVINCE: AN EMPIRICAL STUDY
}

\author{
Lu Chunyang, Zhang Hongmin, Wen Feng \\ Henan University of Urban Construction Henan Pingdingshan 467036
}

KEY WORDS: Cultivated land change; Economic development, Location entropy, Henan province

\begin{abstract}
:
Cultivated land resources are the basic production factors that carry human survival and economic development. Exploring the relationship between cultivated land change and economic development has become a hot issue for scholars.in this paper,The methods of regression analysis, land use elastic coefficient method, location entropy are used to empirically describe the relationship between cultivated land change and economic development.The results show: Since the 20th century, the change of cultivated land area has experienced three distinct stages of change, showing a process of recovery, decline, and steady evolution in Henan Province. The per capita cultivated land area is characterized by an upward trend, and the per capita cultivated land area is increasing year by year. In general, the intensive use of cultivated land in Henan Province is still not high, but the momentum of a sharp decline in cultivated land is basically controlled. The change of cultivated land area and economic development showed a four-time curve fitting relationship, which indicates that the path dependence of economic development on cultivated land occupation still exists, and cultivated land supports the rapid development of economy. The research results of the relationship between cultivated land change and economic development by using location entropy show that the spatial layout of the urban area is less than 0 , and the regularity is not strong.The location where the location entropy is between 0-1 is mainly located in the central part of Henan Province; The cities with location entropy greater than 1 are mainly located in the eastern part of Henan.
\end{abstract}

\section{The introduction}

Cultivated land resource is human survival and economic development of the basic factors of production.But with the rapid development of urbanization and industrialization, the problem of cultivated land loss caused extensive concern of the government and academic circle ${ }^{[1]}$.Foreign scholars of regional land use and interactive relationship of economic and social development have a profound understanding of, and cobb Douglas production function model is adopted at quantitatively analyzes the factors such as land, capital and labor contribution to economic growth.Chinese scholars on the relationship between the cultivated land change and economic development also made the positive exploration, and achieved some research results ${ }^{[2-3]}$.At present, scholars generally agree that the cultivated land resources reducing is one of the major cause of economic development, showing the trend of arable land decrease with economic development.Some scholars think that the cultivated land change and the economic development of a linear negative correlation between ${ }^{[4]}$, some scholars of parts, according to a study by a rapid decline in cultivated land with the increase of the per capita GDP, characterized by exponential decline trend ${ }^{[5]}$.Also the scholar thinks, between cultivated land and economic development showed a similar to the environmental kuznets inverted "U" type curve characteristics, such as Mr Fukuda of tianjin, shandong [6], gui-shan Yang of the Yangtze river delta economic developed regions such as arable land loss and economic development relationship of quantitative analysis, verify the existence of similar kuznets curve ${ }^{[7]}$.How to 
guarantee the rapid economic growth at the same time, the protection of cultivated land red line, ensure food security in China, is one of the goals of the national macroeconomic regulation and control, is also the focus of the scholars research the problem ${ }^{[8]}$.From the perspective of the existing research results, the scholars focus on economically developed areas, there are also scholars of the west such as shaanxi ${ }^{[9-10]}$ of chongqing, gansu ${ }^{[11]}$ and other areas of the relationship between cultivated land change and economic development.But for food core areas of central China, there are few related research.Based on the national food is one of the core area of henan province as the empirical object, analyze the correlation between cultivated land change and economic development, not only to improve the correlation between cultivated land change and economic development to provide more material, at the same time mining area of cultivated land change the general characteristics of this kind, for the regional resources, economic and social sustainable development to provide the reference.

\section{Materials and methods}

\section{1 data source}

Required in the study of social and economic data in 2001-2014 in henan province from henan statistical yearbook (2015) ${ }^{[12]}$.Land data from the survey data of land use change of henan province and the 30 years of reform and opening-up, henan: 1978-2008" $"[13]$.

\section{2 research method}

(1) regression analysis

Regression analysis method are used to indicate the relation between economic growth and farmland.Regression analysis is to explore the random variables $\mathrm{Y}$ and $\mathrm{x}$ (it may be a multi-dimensional vector), the relationship between the independent variable $\mathrm{x}$ was determined, the value of the dependent variable $\mathrm{Y}$ is not as sure, but according to certain statistical regularity (i.e., the distribution of the random variable $\mathrm{Y}$ ) values, then we will be expressed as the relationship between them:

$$
Y=f(x)+\varepsilon
$$

$\mathrm{f}(\mathrm{x})$ is a function of a firm, called the regression function, epsilon as random, and epsilon obey $\mathrm{N}(0$, sigma 2).In this paper, the dependent variable variables for growth, with GDP (Y), said the argument for the cultivated land area is variable, with (x).

\section{(2)Land of elasticity}

By scholars such as wang in the land of the research on relationship between land supply and economic growth of shenzhen ${ }^{[14]}$ elasticity coefficient, the elastic coefficient of land use in arable land loss and annual GDP growth rate, the ratio between the reflected the change of land use of intensive and sustainable situation.Land use calculation formula of the elastic coefficient of $\mathrm{T}$ as follows:

$\mathrm{T}=$ decrement in $\mathrm{X} / \mathrm{Y}$ in the annual

growth rate

For the elastic coefficient of land use type, T, X years decrement for arable land loss, $\mathrm{Y}$ annual growth rate of GDP growth rate.

\section{(3)Location entropy}

Location entropy is put forward by ha gheit and is used to measure the spatial distribution of the elements in the area, reflect a certain degree of sector specialization, as well as an area in the region of the high level of the position and role.In this paper, application of location entropy to analysis of henan economic development around the city to the influence degree of the farmland change.

$$
M i=\frac{P i}{\sum_{i=1}^{n} P i} \quad N i=\frac{G i}{\sum_{i=1}^{n} G i} \quad Q i=\frac{M i}{N i}
$$

Formula: Pi for I city cultivated land reduction, $\mathrm{Mi}$ of the ith a city cultivated land area of the provincial total loss of arable land, reduce the proportion of total area;Gi for the I the city at the same time the increase in GDP, Ni for the ith a city GDP increase the province to increase the proportion of total GDP;Qi is I, is the location entropy value.

\section{Regional research}

Henan Province is located in the middle and lower reaches of the Yellow River, with a total land area of $165,500 \mathrm{~km}^{2}$. Henan Province has 18 cities and 108 counties (cities). In 2014, the total 
population of the province was 10.66 million, of which 48.19 million people were urban, the urbanization rate was $45.2 \%$, which was 9.57 percentage points lower than the national urbanization rate in the same period. During the same period, the province achieved a GNP of 3707.2 billion yuan, the proportion of primary, secondary and tertiary industries was 11.91:50.99:37.10, and the per capita GDP was 37072 yuan, which was $79.50 \%$ of the national per capita GDP in the same period. The grain output is 57.723 million tons, accounting for $9.51 \%$ of the national grain output. It not only feeds more than 1/13 of the population in China, but also exports 15 billion $\mathrm{kg}$ of raw grain and manufactured products every year, making a positive contribution to food security in China.

According to the Implementation Opinions of Henan Grain Production Core Area Construction Plan, by 2020 the grain production capacity of Henan Province will be increased to 65 billion $\mathrm{kg}$, accounting for nearly one third of the total growth of the country, which puts forward higher requirements for the protection of cultivated land in the whole province. At present, Henan Province is in an important period of strategic opportunity to speed up the construction of the Central Plains Economic Zone, and the demand for construction land in structural adjustment, urban and rural construction, social development and other aspects is increasing rigidly. How to coordinate the relationship between economic development and cultivated land protection and ensure the status of Henan Province in the national food security strategy, it is necessary to scientifically define the relationship between cultivated land change and economic development in Henan Province, in order to provide decision-making reference for achieving the win-win goal of cultivated land protection and economic development.

\section{The results and analysis}

\subsection{Analysis of cultivated land change}

From 2001 to 2014, the cultivated land resources in Henan Province changed from 6907.3 $* 10^{3} \mathrm{hm}^{2}$ in 2001 to $8124.66 * 10^{3} \mathrm{hm}^{2}$ in 2014 , and the number of cultivated land increased by 1217.36 $* 10^{3} \mathrm{hm}^{2}$ in 13 years. During this period, the largest area of cultivated land was in 2009, reaching $8192.01 * 10^{3} \mathrm{hm}^{2}$, and the smallest was $6907.3 * 10^{3} \mathrm{hm}^{2}$ in 2001 . As can be seen from Fig. 1 , in general, the change of cultivated land in Henan Province has experienced three stages: obvious decline, rebound and stabilization. In the declining stage (2002-2003), the cultivated land area decreased by $75.54 * 10^{3} \mathrm{hm}^{2}$, and the annual reduction rate of cultivated land was $1.04 \%$. In the rising stage (2003-2004, 2008-2009), the cultivated land area rose rapidly. During these two periods, the government strengthened the protection of cultivated land and controlled the momentum of rapid and sharp decline of cultivated land resources. The net increase of cultivated land area was 739.09 $* 10^{3} \mathrm{hm}^{2}$ and $265.61 * 10^{3} \mathrm{hm}^{2}$, respectively. Stable stage (2004-2008, 2009-2014), stable period of cultivated land change. During these two periods, the cultivated land area fluctuated little, and the cultivated land area fluctuated around $7926 * 10^{3}$ $\mathrm{hm}^{2}$ and $8192 * 10^{3} \mathrm{hm}^{2}$, respectively. 


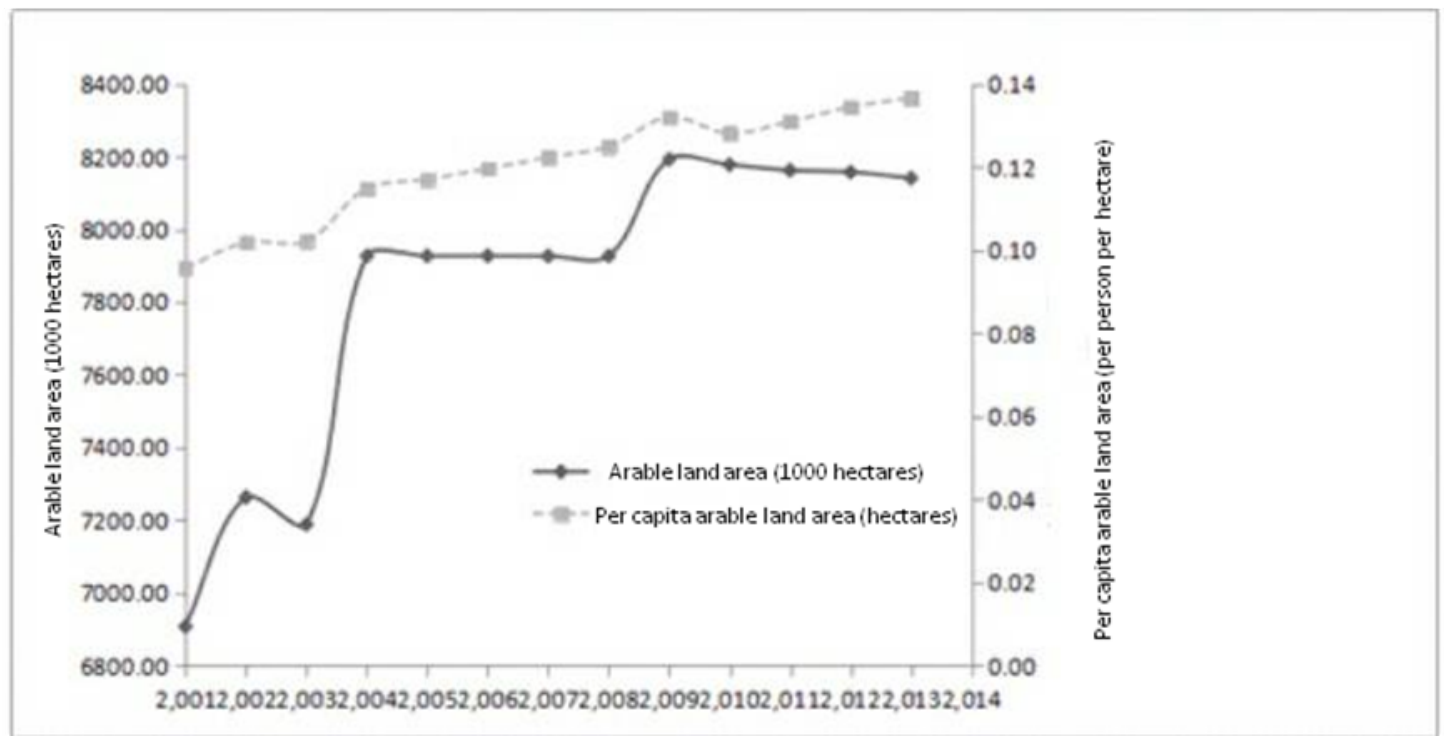

Fig.1 the change of cultivated land area and per cultivated land in Henan Province during 2001-2014

Per capita arable land area of cultivated land area changes with the different change characteristics, basic keep rising trend.Per capita arable land area in henan province by 2001 between 2014 and $0.10 \mathrm{hm}^{2} / 0.14 \mathrm{hm}^{2}$ / person.Arable land per capita is rising with the speeding up of urbanization, the rural population to cities and towns, the second and third industry to town gathered themselves together, and make the rural population is declining, the per capita arable land is gradually increased.

\subsection{Cultivated land area and the relationship}

\section{between GDP}

The contribution of cultivated land change to economic development is mainly reflected in the changes of GDP and output value of various industries. This paper mainly uses GDP to reflect the level of economic development. With the change of cultivated land area, Henan's GDP increased from 553.301 billion yuan in 2001 to 3493.824 billion yuan in 2014 , with an average annual growth rate of 226.196 billion yuan and an average annual growth rate of $40.88 \%$. Using SPSS software, the correlation between total cultivated land area and GDP in Henan Province was analyzed.

In theory, in the low level of economic development stage, economic growth of the cultivated

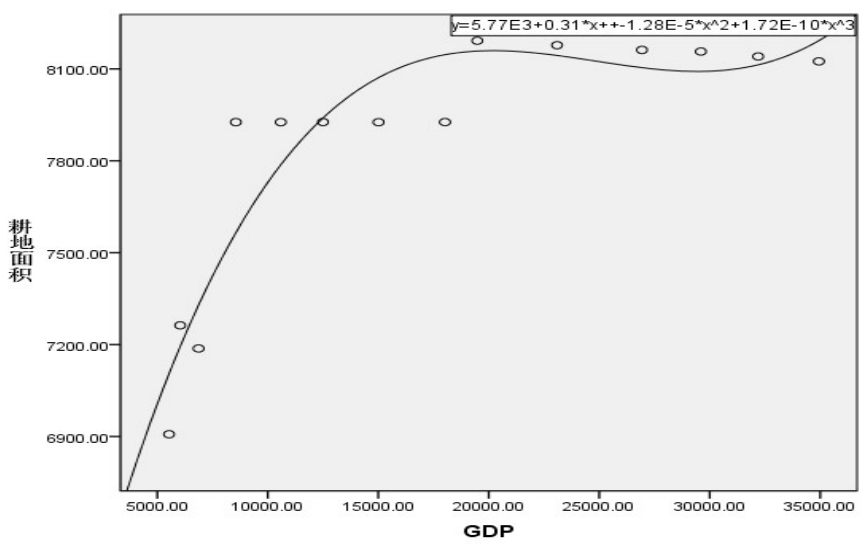

Fig.2 the relationship between cultivated land area and GDP 
land utilization is very limited, with the rapid urbanization and industrialization development, economic development pressure surge of farm land, cultivated land loss rate increases with the constant improvement of the level of economic development.In the higher stages of economic development is relatively stable, on the one hand, the cultivated land protection consciousness constantly strengthen, on the other hand, as the technology progress and the optimization of industrial structure, economic development to cultivated land utilization will be leveled off, the trend of cultivated land loss gradually reversed.From figure 2 changes of cultivated land and GDP related curve can be seen that, between cultivated land change and economic development of henan province is still not fully presents the "inverted U" curve relationship, GDP growth in the demand for cultivated land trend appears fluctuating characteristics, GDP growth are still unable to get rid of the dependence on cultivated land.

\subsection{The relationship between the annual change rate and GDP rate}

Under the background of overall correlation between cultivated land area change and economic development in Henan Province, there are also different characteristics of change. Affected by macroeconomic background and policy, the economic effect of cultivated land resources used for non-agricultural construction needs a certain time to be completed and operated, that is to say, it has a certain time lag. Therefore, taking GDP change rate and cultivated land change rate as the main indicators, the annual change rate of cultivated land area in Henan Province is the largest in $2004-10.28 \%$, while the peak period of GDP growth appears in 2004 and 2005 , with annual growth rates of $24.55 \%$ and $23.77 \%$, respectively.

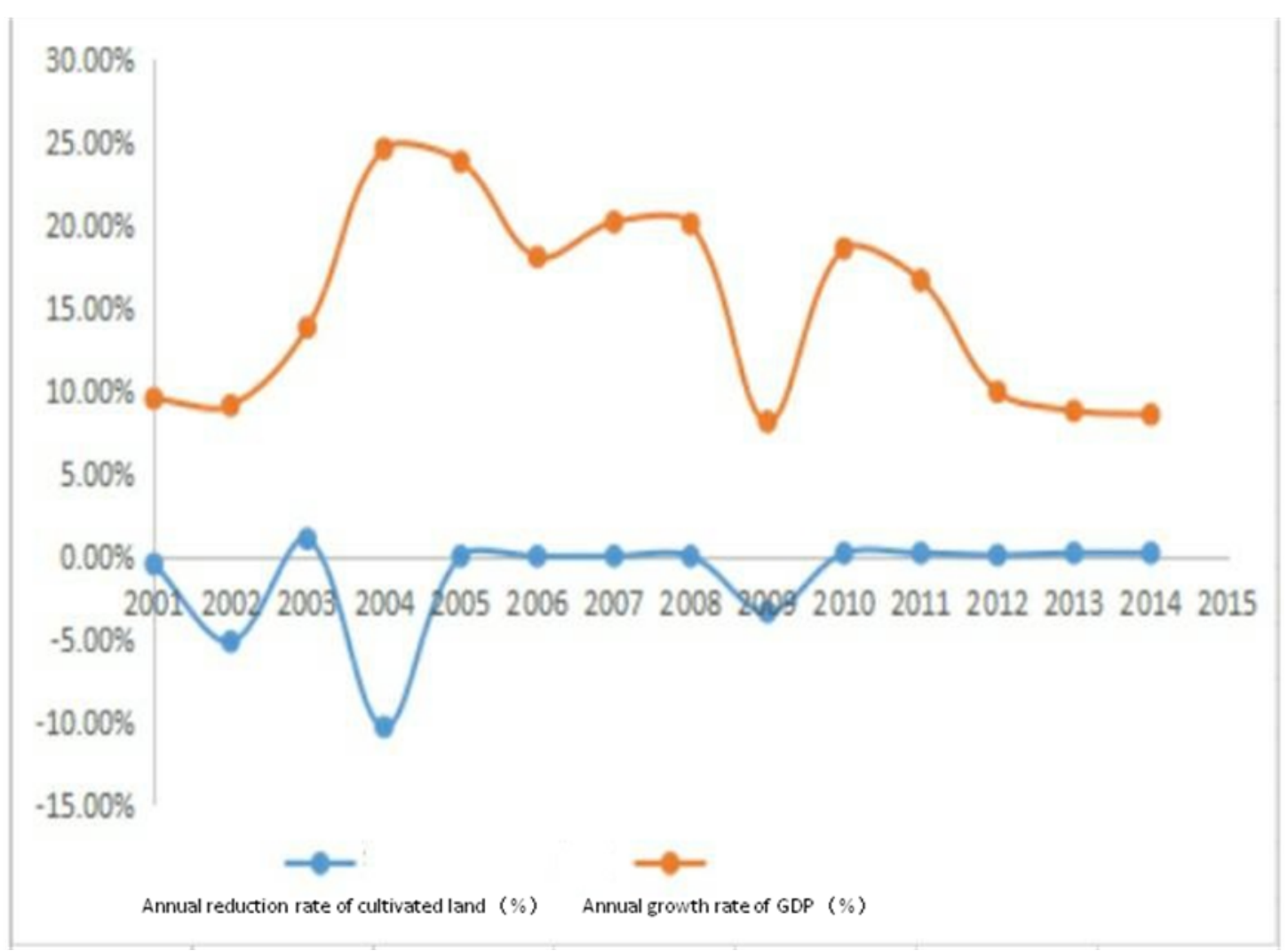

Fig. 3 the relationship between annual reduction rate of cultivated land area and annual growth rate

The table 1 shows that since 2005, the elastic coefficient of land use change of henan province basic is zero, that land collapse in the momentum of the basic under control.
Elastic coefficient of land use of henan province since 2010 has obvious changes in volatility characteristics, intensive degree of cultivated land use of henan province is not high, the elasticity coefficient of land use increased from 0.010 to 0.023 . 
Tab.1 the change of land use elasticity coefficient in Henan Province

\begin{tabular}{cccccccc}
\hline & $\begin{array}{c}\text { In } \\
\text { cultivated } \\
\text { land loss } \\
(\%)\end{array}$ & $\begin{array}{c}\text { Annual } \\
\text { GDP } \\
\text { growth rate } \\
(\%)\end{array}$ & $\begin{array}{c}\text { The elastic } \\
\text { coefficient } \\
\text { of land use } \\
(\mathrm{T})\end{array}$ & year & $\begin{array}{c}\text { In } \\
\text { cultivated } \\
\text { land loss } \\
(\%)\end{array}$ & $\begin{array}{c}\text { Annual } \\
\text { GDP } \\
\text { growth rate } \\
(\%)\end{array}$ & $\begin{array}{c}\text { The elastic } \\
\text { coefficient } \\
\text { of land use }\end{array}$ \\
\hline 2001 & $-0.47 \%$ & $9.50 \%$ & -0.049 & 2008 & $0.00 \%$ & $20.02 \%$ & 0.000 \\
2002 & $-5.15 \%$ & $9.08 \%$ & -0.567 & 2009 & $-3.35 \%$ & $8.11 \%$ & -0.413 \\
2003 & $1.04 \%$ & $13.79 \%$ & 0.075 & 2010 & $0.18 \%$ & $18.54 \%$ & 0.010 \\
2004 & $-10.28 \%$ & $24.55 \%$ & -0.419 & 2011 & $0.19 \%$ & $16.62 \%$ & 0.011 \\
2005 & $0.00 \%$ & $23.77 \%$ & 0.000 & 2012 & $0.06 \%$ & $9.91 \%$ & 0.006 \\
2006 & $0.00 \%$ & $18.03 \%$ & 0.000 & 2013 & $0.20 \%$ & $8.76 \%$ & 0.022 \\
2007 & $0.01 \%$ & $20.14 \%$ & 0.000 & 2014 & $0.20 \%$ & $8.53 \%$ & 0.023 \\
\hline
\end{tabular}

Note: the 2001, 2002, 2004 and 2009, the increase of cultivated land to some extent, the decrement in negative.For comparison, the article unified with positive said.

\subsection{Henan economic development and cultivated} land area changes of location entropy

The spatial and temporal characteristics of cultivated land change and economic development in Henan Province are explored by using the formula of location entropy. It is divided into three periods: 2001-2005, 2006-2010 and 2011-2014. By calculating the location entropy of 18 cities in Henan Province, it can be divided into three types: location entropy is less than 0 , location entropy is between 0-1 and location entropy is greater than 1 . Among them, the location entropy from 2001 to 2005 is positive.

(1) Location Entropy < 1: There are 11 cities whose location Entropy is between 0 and 1 . According to the size of location Entropy, they are Luohe City, Sanmenxia City, Anyang City, Xuchang City, Puyang City, Jiyuan City, Hebi City,
Luoyang City, Jiaozuo City, Pingdingshan City and Zhengzhou City. This type of economic development has little effect on the reduction of cultivated land. The average of location entropy is 0.52 , which is below the average level of the whole province.

(2) $1<$ Location Entropy: There are seven cities in this stage. They are Xinyang City, Kaifeng City, Shangqiu City, Xinxiang City, Zhoukou City, Zhumadian City and Nanyang City according to the size of Location Entropy. The maximum value belongs to Xinyang City, whose value is about 5.56 . The non-agricultural use of cultivated land has resulted in a large reduction of cultivated land area. With the rapid development of economy, the economic development of these seven cities has a greater impact on the reduction of cultivated land area.

Tab.2 the location entropy of cultivated land and economic development during 2001-2005

\begin{tabular}{cccccc}
\hline region & $\begin{array}{c}\text { Arable land, } \\
\text { reduce the area } \\
\text { of }\left(10^{3} \mathrm{hm}^{2}\right)\end{array}$ & $\begin{array}{c}\text { The } \\
\text { proportion }\end{array}$ & $\begin{array}{c}\text { GDP increase } \\
\text { (one hundred } \\
\text { million yuan) }\end{array}$ & $\begin{array}{c}\text { The } \\
\text { proportion }\end{array}$ & $\begin{array}{c}\text { Location } \\
\text { entropy }\end{array}$ \\
\hline Henan province & -1019.04 & 1.00 & 5054.41 & 1.00 & 1.00 \\
Zhengzhou city & -40.23 & 0.04 & 832.40 & 0.16 & 0.24 \\
Kaifeng city & -64.89 & 0.06 & 155.66 & 0.03 & 2.07 \\
Luoyang city & -44.41 & 0.04 & 647.21 & 0.13 & 0.34 \\
Pingdingshan & -13.34 & 0.01 & 265.65 & 0.05 & 0.25 \\
Anyang city & -42.23 & 0.04 & 277.63 & 0.05 & 0.75 \\
Hebi city & -6.25 & 0.01 & 91.42 & 0.02 & 0.34 \\
\hline
\end{tabular}




\begin{tabular}{cccccc}
\hline Xinxiang city & -79.59 & 0.08 & 235.47 & 0.05 & 1.68 \\
Jiaozuo city & -17.17 & 0.02 & 327.31 & 0.06 & 0.26 \\
Puyang city & -22.64 & 0.02 & 164.53 & 0.03 & 0.68 \\
Xuchang city & -38.84 & 0.04 & 279.28 & 0.06 & 0.69 \\
Luohe city & -23.78 & 0.02 & 139.82 & 0.03 & 0.84 \\
Sanmenxia & -23.94 & 0.02 & 153.99 & 0.03 & 0.77 \\
Nanyang city & -100.83 & 0.10 & 477.15 & 0.09 & 1.05 \\
Shangqiu city & -95.94 & 0.09 & 242.40 & 0.05 & 1.96 \\
Xinyang city & -274.33 & 0.27 & 244.88 & 0.05 & 5.56 \\
Zhoukou city & -70.46 & 0.07 & 222.10 & 0.04 & 1.57 \\
Zhumadian & -51.81 & 0.05 & 194.74 & 0.04 & 1.32 \\
Jiyuan city & -8.36 & 0.01 & 78.10 & 0.02 & 0.53 \\
\hline
\end{tabular}

Location Entropy $<0$ : There are four cities in this period. According to the location entropy, Xuchang City, Sanmenxia City, Kaifeng City and Shangqiu City are ranked from large to small. The location entropy of these four cities is negative, which indicates that the economic development of these areas contributes to the increase of cultivated land area.

$0<$ Location Entropy < 1: There were 7 cities in this period. According to the order of location entropy from big to small, they are Zhoukou City, Pingdingshan City, Luoyang City, Luohe City, Jiaozuo City, Zhengzhou City and Anyang City. The location entropy value of Anyang is 0.06 , which indicates that the economic development of Anyang has little effect on the change of cultivated land area. The mean value of location entropy is 0.32 in these five years, which indicates that the development of the economic level of these cities has little influence on the change of cultivated land area.

$1<$ Location Entropy: There are 7 cities in this period. According to the order of location entropy from big to small, they are Zhumadian City, Xinyang City, Hebi City, Nanyang City, Puyang City, Xinxiang City and Jiyuan City. The location entropy of Zhumadian City is the largest, which is about 6.05 , far more than that of the other six cities. The average value of this period is about 3.14, which shows that economic development has a greater impact on the reduction of cultivated land area.

Tab.3 the location entropy of cultivated land and economic development during 2006-2010

\begin{tabular}{cccccc}
\hline region & $\begin{array}{c}\text { Arable land, } \\
\text { reduce the area } \\
\text { of }\left(10^{3} \mathrm{hm}^{2}\right)\end{array}$ & $\begin{array}{c}\text { The } \\
\text { proportion }\end{array}$ & $\begin{array}{c}\text { GDP increase } \\
\text { (one hundred } \\
\text { million yuan) }\end{array}$ & $\begin{array}{c}\text { The } \\
\text { proportion }\end{array}$ & $\begin{array}{c}\text { Location } \\
\text { entropy }\end{array}$ \\
\hline Henan province & -250.85 & 1.00 & 10596.39 & 1.00 & 1.00 \\
Zhengzhou city & -6.94 & 0.03 & 2027.41 & 0.19 & 0.14 \\
Kaifeng city & 10.60 & -0.04 & 451.87 & 0.04 & -0.99 \\
Luoyang city & -8.97 & 0.04 & 986.60 & 0.09 & 0.38 \\
Pingdingshan & -6.60 & 0.03 & 635.43 & 0.06 & 0.44 \\
Anyang city & -1.75 & 0.01 & 669.59 & 0.06 & 0.11 \\
Hebi city & -18.08 & 0.07 & 207.45 & 0.02 & 3.68 \\
Xinxiang city & -21.12 & 0.08 & 549.95 & 0.05 & 1.62 \\
Jiaozuo city & -3.95 & 0.02 & 546.83 & 0.05 & 0.31 \\
Puyang city & -13.37 & 0.05 & 319.16 & 0.03 & 1.77 \\
Xuchang city & 0.41 & 0.00 & 597.95 & 0.06 & -0.03 \\
Luohe city & -2.54 & 0.01 & 300.21 & 0.03 & 0.36 \\
\hline
\end{tabular}




\begin{tabular}{cccccc}
\hline Sanmenxia & 1.00 & 0.00 & 462.27 & 0.04 & -0.09 \\
Nanyang city & -62.90 & 0.25 & 750.31 & 0.07 & 3.54 \\
Shangqiu city & 11.61 & -0.05 & 492.81 & 0.05 & -1.00 \\
Xinyang city & -47.26 & 0.19 & 503.48 & 0.05 & 3.97 \\
Zhoukou city & -6.62 & 0.03 & 550.56 & 0.05 & 0.51 \\
Zhumadian & -68.98 & 0.27 & 481.79 & 0.05 & 6.05 \\
Jiyuan city & -5.39 & 0.02 & 162.35 & 0.02 & 1.40 \\
\hline
\end{tabular}

From 2011 to 2014, the economy of Henan Province is in a steady growth stage, with an average value of about $15.84 \%$, while the cultivated land area is in a stable period, which is $8146 * 103 \mathrm{hm} 2$.

Location Entropy $<0$ : During this period, there were three cities, Pingdingshan City, Xinxiang City and Sanmenxia City, according to the order of location Entropy from big to small. The average of location entropy of the three cities is about - 0.21. Location entropy of Sanmenxia City is the smallest, about - 0.3. It is indicated that the economic development of these three regions during the four years has promoted the increase of cultivated land area.

$0<$ Location Entropy $<1$ : During this period, the average value of Location Entropy of seven cities is about 0.35 . According to the order of Location Entropy from big to small, they are Luohe City, Zhengzhou City, Luoyang City, Puyang City, Jiaozuo City, Xinyang City and Anyang City. The location entropy of Luohe City and Zhengzhou City is larger, 0.99 and 0.98 respectively, while the average value of the other five cities is around 0.096 , indicating that the economic development of these five regions has little effect on the change of cultivated land area.

$1<$ Location Entropy: There are 8 cities in this period. According to location entropy, Hebi
City, Zhumadian City, Jiyuan City, Kaifeng City, Nanyang City, Shangqiu City, Zhoukou City and Xuchang City are arranged from large to small. During the four years, the average value of location entropy was 2.01, and Hebi City had the largest, which was 3.62, indicating that economic development had a greater impact on cultivated land area.

Since 2011, there are seven cities whose location entropy has not changed, namely Anyang City, Jiaozuo City, Luoyang City, Zhengzhou City, Luohe City, Nanyang City and Zhumadian City. In the past 14 years, the location entropy of the first five cities is between 0 and 1. Five cities, including Zhengzhou, the capital of the province, belong to the economically developed areas. In 2014, the GDP of these five cities accounted for $52 \%$ of the total GDP of the province, which effectively promoted the economic development of the province. Although the economic development consumed a large amount of cultivated land resources, with the implementation of the policy of increasing and decreasing linkages, the cultivated land area has been improved. The change of product is almost unaffected. However, in the same period, the location entropy values of Nanyang and Zhumadian have remained greater than 1 , which indicates that the economic development of these two cities has been strong for cultivated land.

Tab.4 the location entropy of cultivated land and economic development during 2006-2010

\begin{tabular}{cccccc}
\hline region & $\begin{array}{c}\text { Arable land, } \\
\text { reduce the area } \\
\text { of }\left(10^{3} \mathrm{hm}^{2}\right)\end{array}$ & $\begin{array}{c}\text { The } \\
\text { proportion }\end{array}$ & $\begin{array}{c}\text { GDP increase } \\
\text { (one hundred } \\
\text { million yuan) }\end{array}$ & $\begin{array}{c}\text { The } \\
\text { proportion }\end{array}$ & $\begin{array}{c}\text { Location } \\
\text { entropy }\end{array}$ \\
\hline Henan province & 37.24 & 1.00 & 8007.21 & 1.00 & 1.00 \\
Zhengzhou city & 8.23 & 0.22 & 1797.14 & 0.22 & 0.98 \\
Kaifeng city & 3.96 & 0.11 & 419.64 & 0.05 & 2.03 \\
\hline
\end{tabular}


The International Archives of the Photogrammetry, Remote Sensing and Spatial Information Sciences, Volume XLII-3/W10, 2020 International Conference on Geomatics in the Big Data Era (ICGBD), 15-17 November 2019, Guilin, Guangxi, China

\begin{tabular}{cccccc}
\hline Luoyang city & 0.52 & 0.01 & 581.81 & 0.07 & 0.19 \\
Pingdingshan & -0.07 & 0.00 & 152.56 & 0.02 & -0.10 \\
Anyang city & 0.02 & 0.00 & 305.20 & 0.04 & 0.01 \\
Hebi city & 3.06 & 0.08 & 181.68 & 0.02 & 3.62 \\
Xinxiang city & -0.44 & -0.01 & 428.40 & 0.05 & -0.22 \\
Jiaozuo city & 0.21 & 0.01 & 401.69 & 0.05 & 0.11 \\
Puyang city & 0.23 & 0.01 & 356.27 & 0.04 & 0.14 \\
Xuchang city & 2.76 & 0.07 & 498.49 & 0.06 & 1.19 \\
Luohe city & 0.87 & 0.02 & 189.46 & 0.02 & 0.99 \\
Sanmenxia & -0.29 & -0.01 & 209.61 & 0.03 & -0.30 \\
Nanyang city & 3.95 & 0.11 & 473.26 & 0.06 & 1.79 \\
Shangqiu city & 3.20 & 0.09 & 389.27 & 0.05 & 1.77 \\
Xinyang city & 0.06 & 0.00 & 499.66 & 0.06 & 0.03 \\
Zhoukou city & 4.70 & 0.13 & 582.26 & 0.07 & 1.74 \\
Zhumadian & 5.19 & 0.14 & 446.53 & 0.06 & 2.50 \\
Jiyuan city & 1.08 & 0.03 & 107.10 & 0.01 & 2.17 \\
\hline
\end{tabular}

Can see from figure (figure 4, figure 5, figure 6), city distribution of location entropy less than zero is not very stable, location entropy between 0 and 1 are mainly distributed in henan province in central cities, location entropy is greater than 1 are mainly distributed in the eastern cities.

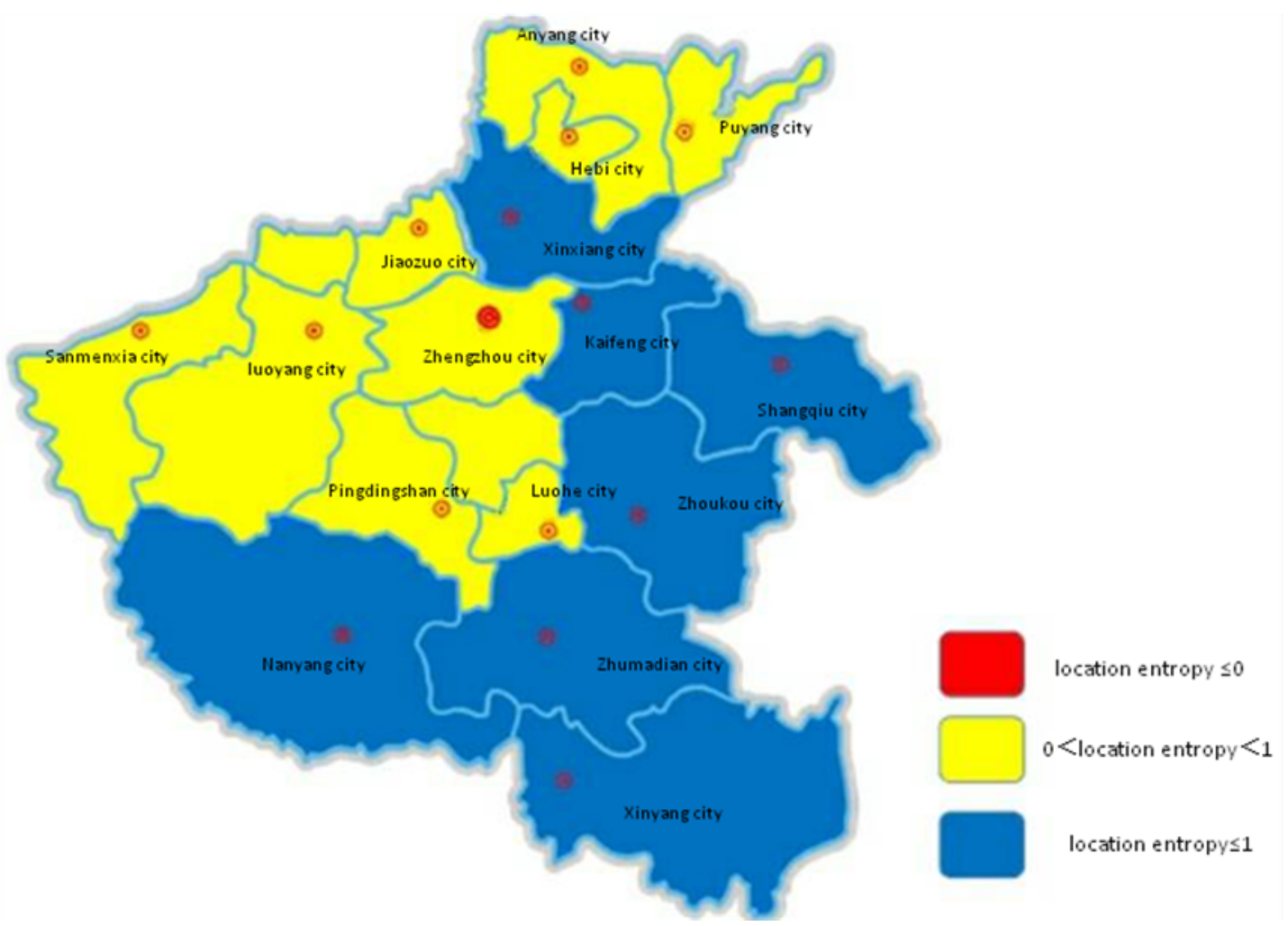

Fig.4 the graph of location entropy of cultivated land and economic development during 2001-2005 


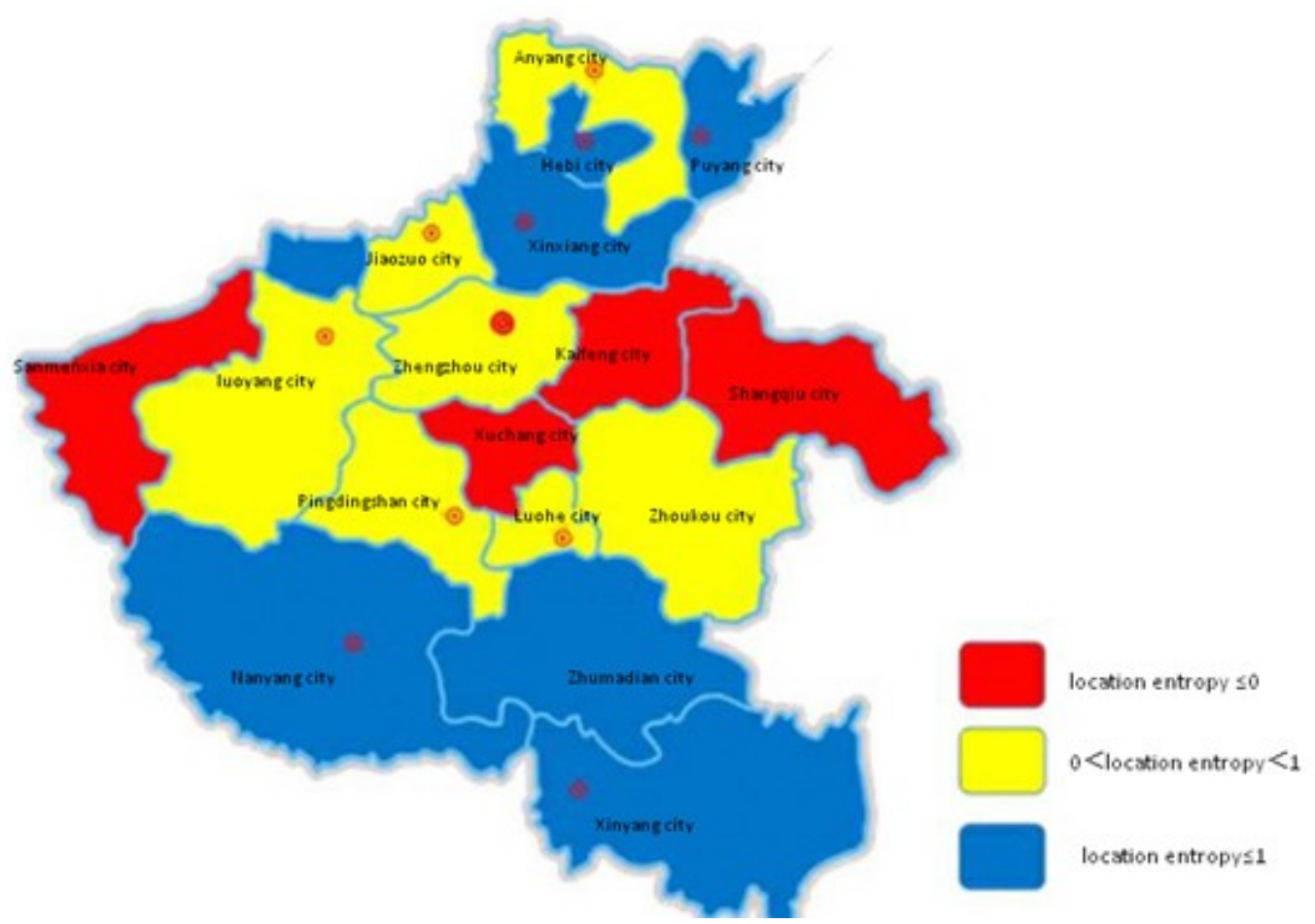

Fig.5 the graph of location entropy of cultivated land and economic development during 2006-2010

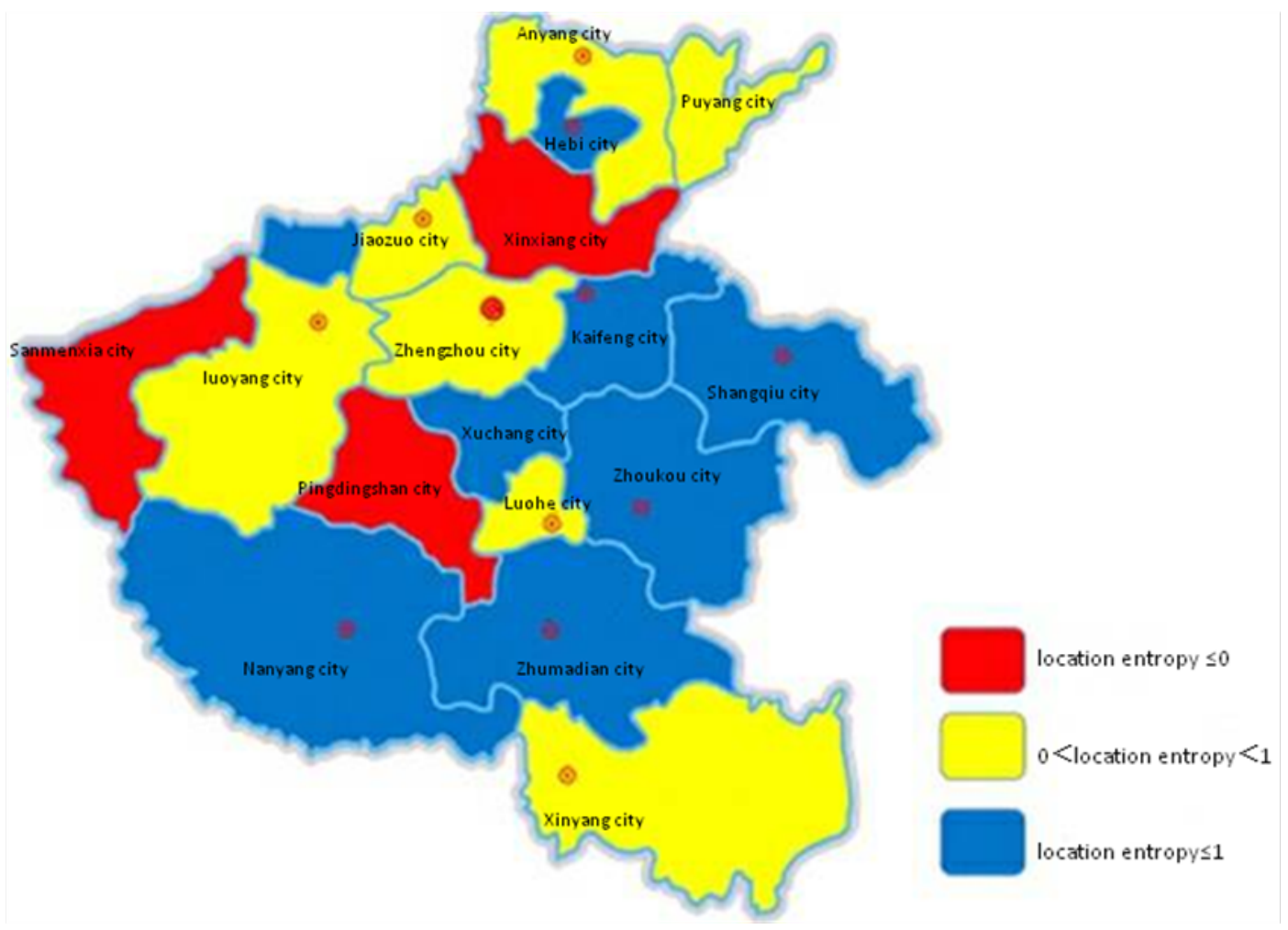

Fig.6 the graph of location entropy of cultivated land and economic development during 2011-2014

\section{Conclusion and discussion}

Through the analysis of temporal and spatial characteristics of cultivated land change and economic development in Henan Province. It is known that:
(1) Since the 20th century, the change of cultivated land area in Henan Province has experienced a process of recovery, decline and steady evolution, while the per capita cultivated land area shows an upward trend, and the per capita cultivated 
land area shows an increasing trend year by year.

(2) Generally speaking, the intensive degree of cultivated land utilization in Henan Province is not high, but the momentum of the sharp decline of cultivated land is basically controlled. The relationship between cultivated land area and economic development is quadric curve, and the economic development has not yet got rid of the dependence on cultivated land occupation.

(3) The results of location entropy of cultivated land change and economic development in Henan Province show that the distribution of cities with location entropy less than 0 is scattered; the cities with location entropy between 0 and 1 are mainly concentrated in the central part of Henan Province; the cities with location entropy greater than 1 are mainly concentrated in the eastern part of Henan Province.

At present, Henan Province is in the critical period of building the "Four Henan" in an all-round way, and at the same time, it is also the key period of further consolidating the core area of national grain production. Therefore, in pursuit of rapid economic development, we must explore a win-win way of economic development and food security.

We should not only accelerate the process of

\section{REFERENCES}

[1]Regional difference analysis of correlation between cultivated land change and socio-economic development in Hao Runmei, Chailing Hohhot [J]. Journal of Inner Mongolia Normal University (Philosophy and Social Sciences Edition), 2014, (43) 2:121-124.

[2]Pan Peipei, Wang Xiaoxu, Yang Guishan, et al. Spatial-temporal change pattern of cultivated land quality in areas with rapid economic development [J]. Geographic and geographic information science, 2015, (31) 4:65-70.

[3]Wang Zhongjun. Cointegration and causality between cultivated land resource change and economic development in Xi'an [J]. Shaanxi Agricultural Science, 2013, 3:197-199.

[4] Yang Yong, Ren Zhiyuan. The relationship industrialization and urbanization to promote stable increase in grain production, but also promote new urbanization through agriculture. Firstly, the incentive mechanism of cultivated land protection should be established. According to the level of regional social and economic development, the compensation standard of cultivated land protection is reasonably determined to mobilize the enthusiasm of the government, farmers and other stakeholders in cultivated land protection. Secondly, the evaluation system of intensive use of cultivated land should be established. Establish the method system and evaluation criteria of cultivated land resource utilization, and provide a scientific and effective operation platform for improving the level of intensive use of cultivated land. Thirdly, we should strengthen the research and development of land-saving technology, innovate economic development model and economic distribution mechanism, and pay attention to the ecological protection of cultivated land. Finally, the new model of land consolidation plus land consolidation is constantly explored. Increase the reclamation of rural idle construction land, rural residential areas and other land.

between dynamic change of cultivated land and socio-economic development in Xi'an [J]. Arid Region Research, 2007, 24 (3): 316-320.

[5] Li Zhaofu, Yang Guishan, Huzhou City, the relationship between cultivated land resources change and economic development in the past 50 years [J]. Chinese Journal of Eco-Agriculture, 2007, 15 (3): 146-149.

[6]Qufutian, Wu Limei. Kuznets Curve Hypothesis and Validation of Economic Growth and Farmland Non-Agriculturalization [J]. Resource Science, 2004, 26 (5): 61-67.

[7]Yang Guishan. Land use/cover change and regional economic development: enlightenment from the study of cultivated land change in the Yangtze River Delta in recent 50 years [J]. Journal of Geography, 2004, 59:41-46

[8]Gao Jinlan, Ma Xiaoqun, Zhang Qingguo, et al. Trend change of grain yield per unit area and impact 
analysis of major economic factors in Anhui Province

[J]. China Agricultural Bulletin, 2013, 29 (3):

108-115.

[9]Ma Wenbo, Li Shiping, Chen Yu. Study on the dynamic relationship between cultivated land quantity change and economic development --- Take Shaanxi Province as an example $[\mathrm{J}]$. Resources and environment in arid areas, 2012, 26 (5): 181-186.

[10]Lu Chunyang, Yang Qingyuan, Wenfeng, et al. Empirical analysis of the correlation between cultivated land area change and economic development in Chongqing metropolitan area [J]. Journal of Southwest University (Natural Science Edition), 2008, 30 (10): 146-150.

[11] Wang Haihong, Ma Qiong, Fu Shibo, et al. Study on the relationship between cultivated land area change and population and economic development in arid and semi-arid areas of Northwest China - Take Gansu Province as an example [J]. Resources and environment in arid areas, 2011, 25 (1): 74-79.

[12]Henan Statistical Bureau. Henan Statistical Yearbook (2010) [M]. Beijing: China Statistical Publishing House, 2010.

[13]Henan Statistical Bureau. Henan Investigation Team of National Statistical Bureau. Thirty Years of Reform and Opening-up in Henan (1978-2008)[M]. Beijing: China Statistical Publishing House, 2008.

[14]Wang Aimin, Liu Jialin, Yin Xiangdong. The relationship between land supply and economic growth in Shenzhen [J]. Tropical Geography, 2005, 25 (1): 19-23. 